\title{
NOS MEANDROS DO FANTÁSTICO: A ERA VITORIANA SEGUNDO
}

\author{
ARTHUR MACHEN
}

\section{ON THE MEANDERS OF THE FANTASTIC: THE VICTORIAN AGE ACCORDING TO ARTHUR MACHEN}

\author{
Shirley de Souza Gomes Carreira ${ }^{1}$
}

- Senhor, tem piedade do cristão que duvida, do incrédulo que gostaria de crer, do escravo da vida que embarca sozinho na noite, sob um firmamento que não clareia mais as lanternas consoladoras da velha esperança.

Huysmans A rebours/ Le drageoir aux épices

\begin{abstract}
RESUMO: Este artigo visa demonstrar como Arthur Machen, autor da segunda metade do século XIX considerado um mestre da literatura de horror incorpora à ficção temas e tropos da Era Vitoriana, utilizando elementos fantásticos como uma forma de desafio às crenças e valores da época. Em $\mathrm{O}$ grande deus Pã ele cria uma ficção em que é possível o contato entre dois mundos, visivel e invisivel. Por meio de uma personagem híbrida e metamórfica, que é o fio condutor da narrativa, Machen promove transgressões que se concretizam na ficção e espelham outras que se dão, secretamente, no mundo empírico. A recepção negativa da novela por parte da crítica refletiu o impacto que ela exerceu na sociedade inglesa do fin-desiècle, pois expôs as entranhas de uma sociedade em que o lar era cultuado, o erotismo era temido e a paixão era tabu.
\end{abstract}

PALAVRAS-CHAVE: Era vitoriana; Fantástico; O grande deus Pã.

ABSTRACT: This article aims to demonstrate how Arthur Machen, author of the second half of the nineteenth century, considered a master of horror literature, incorporates themes and tropes of the Victorian Era into fiction, using fantastic elements as a way of defying the beliefs and values of the time. In The Great God Pan, he creates a fiction in which the contact between two worlds, visible and invisible, is possible. Through a hybrid and metamorphic character, which is the guiding thread of the narrative, Machen promotes transgressions that materialize in the fiction and mirror others that occur, secretly, in the empirical world. The negative critical reception of the novella reflected the impact it had on the English society of the fin-de-siècle, for it exposed the insides of a society in which home was worship-+ped, eroticism was feared, and passion was taboo.

KEYWORDS: Victorian Age; Fantastic; The great god Pan.

\section{Introdução}

\footnotetext{
${ }^{1}$ Doutora em Letras pela UFRJ e professora adjunta da Universidade do Estado do Rio de Janeiro.
} 
A Era Vitoriana, período em que a rainha Alexandrina Victoria (1819-1901), da dinastia de Saxe-Coburg, esteve no trono do Reino Unido da Grã-Bretanha, foi uma época paradoxal. Se, por um lado, testemunhou a solidificação do poderio do império britânico e o auge da Revolução Industrial, por outro, produziu uma verdadeira legião de miseráveis, explorada como mão de obra barata, que vivia amontoada em moradias insalubres, tornandose alvo de doenças infecciosas e epidemias derivadas da falta de higiene e da superpopulação (HOBSBAWN, 1962, p.44).

Mesmo entre as classes abastadas, o paradoxo existiu, pois, sob o véu de um arraigado apego à moral e à religião, havia um "mundo clandestino" em que a licenciosidade, a luxúria e o espiritualismo eram comuns.

No âmbito das relações sociais, o patriarcado continuava a exercer a sua força, cabendo às mulheres o papel de "anjo do lar" (MONTEIRO, 1998, p. 61). Desde a infância até a juventude, eram tuteladas pelos pais, para, posteriormente, serem entregues a outra tutela igualmente masculina: a dos maridos. Como líder do império, a rainha Vitória compartilhava os valores patriarcais, não servindo, portanto, de modelo para aquelas que lutavam por direitos civis. De fato, somente dezoito anos após a sua morte as mulheres puderam exercer o direito de voto. Conforme afirma Monteiro,

A mulher com o perfil assim delineado tinha todo o apoio da rainha Vitória, que atribuía o sucesso do seu reinado à moralidade da corte e à harmonia da vida doméstica. Consequentemente, olhava o movimento em defesa dos Direitos da Mulher como ameaça à virtude do sexo 'frágil'. Tal situação, obviamente, viria a repercutir, ainda que de forma silenciosa, na vida privada, onde a repressão, principalmente a sexual, se agrava e se intensifica (MONTEIRO, 1998, p. 61).

O estilo de vida modelar vitoriano assumiu um caráter controlador, que contrariava a postura pública típica do século anterior. Os corpos passaram a ser disciplinados e vigiados (FOUCAULT, 2010), o que, na realidade, não impedia a transgressão das normas, pois os austeros chefes das famílias rendiam-se ao afloramento do desejo pelo proibido, frequentando bordeis secretamente. As prostitutas, geralmente vistas como anomalias, contraditoriamente, eram consideradas uma contrapartida indispensável à solidez familiar, uma vez que, ao entregarem-se a prazeres proibidos, dando vazão à sensualidade, os homens se tornavam mais aptos a exercer o papel social de esposos e pais. Entretanto, eram eles os mesmos cidadãos que perseguiam implacavelmente os homossexuais, atribuindo-lhes a causa de uma epidemia de sífilis que se espalhou rapidamente no período, e lhes infligindo penas tão severas que os levavam à completa desonra. A completar o cenário, as descobertas científicas e o 
desenvolvimento tecnológico abriam as portas para um devir que simultaneamente atraía e assustava a sociedade vitoriana, pois apontava para saberes que escapavam à vigilância, ao controle.

Nesse panorama, surgiram autores que, por meio da ficção, expressaram suas angústias em relação ao presente e ao futuro, bem como teceram críticas contundentes aos modelos vigentes; críticas essas que se concretizaram na criação de seres duais, que, como um Janus de papel, metaforizavam as contradições da época. Assim, em The Strange Case of Dr. Jekyll and Mr. Hyde, de Stevenson, The Picture of Dorian Gray, de Oscar Wilde, e Frankenstein, de Mary Shelley, por exemplo, o duplo é símbolo do paradoxo, traço mais evidente das relações sociais do período.

Esta breve exposição do contexto socio histórico vitoriano tem por intuito fornecer dados para a compreensão da análise que propomos da novela $O$ Grande Deus Pã, de Arthur Machen, que, imbuído do Zeitgeist, recorre a estratégias utilizadas por autores da época para construir um mundo ficcional que desvela o lado obscuro da sociedade do seu tempo.

\section{O escritor em seu tempo}

Entre o final do século XIX e o início do século XX, Arthur Machen- hoje, quase que totalmente esquecido - teve o seu momento de fama. O autor nasceu em 3 de março de 1863, no País de Gales, mais especificamente em Caerleon, vila às margens do rio Usk e próxima das ruínas da fortaleza romana Isca Augusta. A paisagem da terra natal exerceu grande influência em sua obra, como o próprio autor atesta em sua autobiografia Far off Things: "quanto mais envelheço mais me convenço de que aquilo que alcancei na literatura se deve ao fato de que, ao abrir meus olhos na primeira infância, deparei com uma terra encantada" ". Machen ficou muito impressionado com a descoberta de esculturas e inscrições pagãs, datadas da época da ocupação romana, o que lhe deu a certeza de que naquela região havia algo além do que os olhos eram capazes de ver. $\mathrm{O}$ deus Nodens, cujo templo foi descoberto por volta de 1870, tornou-se uma de suas fontes de inspiração.

Impossibilitado de prosseguir seus estudos em uma universidade, deixou a Hereford Cathedral School já determinado a se tornar um escritor. Mudou-se para Londres em 1884 e lá se manteve precariamente nos anos seguintes, escrevendo histórias curtas para periódicos da

\footnotetext{
${ }^{2}$ Tradução nossa do texto em inglês: "the older I grow the more firmly am I convinced that anything which I may have accomplished in literature is due to the fact that when my eyes were first opened in earliest childhood they had before them the vision of an enchanted land." Disponível em: <http://www.bbc.co.uk/ blogs/wales/entries/df2aac37-4010-305b-8d1c-4f3da5d06e1c >. Acesso em 03 ago. 2018.
} 
época. Alguns desses textos eram exemplares de literatura fantástica, com temas alinhados à literatura gótica e à literatura de horror, tendências bastante exploradas no século XIX. Enquanto se afirmava como escritor, trabalhando como jornalista e escrevendo nas horas vagas, Machen teve a oportunidade de relacionar-se com outros expoentes da elite literária da época, como Oscar Wilde, cujo julgamento afetou profundamente os adeptos do esteticismo.

Com a publicação de $O$ Grande Deus Pã, em 1894, seguido de The Three Impostors ${ }^{3}$, em 1895, começou a tornar-se conhecido. Considerada por muitos como a melhor história de horror de todos os tempos, O Grande Deus Pã foi alvo de uma crítica acirrada, pois o teor altamente sexual da novela e os elementos de horror foram considerados acintosos à moral vitoriana.

Após a morte da esposa, em 1899, Machen filiou-se à Ordem Hermética da Aurora Dourada, a segunda sociedade ocultista mais importante do século $\mathrm{XIX}^{4}$, da qual William B. Yeats e Bram Stoker também foram membros. A ordem floresceu em um período histórico marcado por contradições: de um lado, a obsessão pela moral e pela manutenção dos valores, do outro, a modernização e o avanço científico. Nesse panorama, firmou-se como um contraponto tanto às forças conservadoras quanto ao cientificismo.

Todos esses aspectos da biografia de Machen são relevantes à análise de sua obra, na medida em que esta espelha o seu olhar sobre a época em que viveu. A particularidade da sua escrita, a criatividade empregada na arquitetura de sua ficção, rendeu-lhe a admiração fervorosa do maior ícone da literatura de horror: H. P. Lovecraft, que explicitamente admitiu ter sofrido a influência de Machen na elaboração de alguns dos seus livros. Assim como ele, Lovecraft praticava uma espécie específica de literatura de horror, a weird fiction, cuja condição de existência estava subordinada à capacidade de provocar no leitor um "sentimento de apreensão, e de contato com esferas diferentes e forças desconhecidas" (LOVECRAFT, 1987, p.5). Para Lovecraft, uma boa história de horror deve estar centrada não no fator que provoca o horror, mas no modo como ele é revelado ao leitor. É neste quesito, no domínio do uso ostensivo de elipses - a poética dos vazios, segundo Campra (2016, p.134) - que Machen revela sua maestria.

\section{O grande deus Pã: a sociedade vitoriana através da lupa}

\footnotetext{
${ }^{3}$ Não há tradução para o português.

${ }^{4}$ A primeira foi a Sociedade Teosófica de Helena P. Blavatsky.
} 
Desde sua chegada a Londres, Machen percorria a cidade buscando os temas para suas obras e essas andanças permitiram-lhe filtrar as aparências, trazer à tona as inconsistências do mundo que habitava e transformá-las em ficção. A atmosfera de segredo, de recolhimento, que permeava o cotidiano no século XIX é perceptível em seus textos e, no caso de $O$ Grande Deus Pã, ela está associada à urbe, o lócus horribilis onde boa parte dos acontecimentos da novela se passa. O tropo de uma Londres "oculta" era comum no fin-de-siècle e está presente na obra de outros escritores da época, como Henry James. No caso específico da novela de Machen, esse lado obscuro da cidade está associado aos excessos sexuais, às mortes inexplicadas e à deambulação das personagens por lugares ermos. Em meio aos influxos do decadentismo, Machen, ao seu modo, busca revelar "a alma das coisas", o que está por debaixo do véu do cotidiano. Movido também pelo revival gótico do fin-de-siècle, o autor desenvolveu uma estratégia narrativa que concilia o horror ao fantástico, cuja ocorrência não oblitera de modo algum os aspectos da sociedade vitoriana que o autor insere em sua ficção.

A narrativa gira em torno de um experimento neurológico feito pelo Dr. Raymond, na certeza de que, ao fazê-lo, proporcionaria à jovem Mary, que lhe servira de cobaia, um vislumbre do mundo espiritual, ao que denominava "a visão do Grande Deus Pã". Um amigo, Clarke, a contragosto, é convidado a presenciar a experiência, cujo resultado é catastrófico, uma vez que a jovem acorda da breve cirurgia com estertores de pavor, como se tivesse experimentado o maior horror que alguém já pudesse ter sentido, tornando-se, desde então, mentalmente doente:

\footnotetext{
De repente, se ergueu o som dum suspiro, o sangue voltou a corar o rosto exangue de Maria, os olhos se abriram e brilharam com estranho fulgor. Uma grande admiração se espelhou na face e as mãos se estenderam como para tocar algo invisível. E logo o espanto se converteu em horror, o rosto numa máscara abominável, e o corpo começou a tremer de tal forma que, se diria, era sua alma lutando na prisão carnal. Horrível visão! Clarke se precipitou porta afora, enquanto a jovem caía ao chão, uivando (MACHEN, 1986, p.8).
}

Esse capítulo inicial traz à baila uma questão crucial para os vitorianos: o alcance e o poder da ciência. O desrespeito pela vida humana, no caso, a de Mary, uma jovem que Raymond resgatara das ruas, em favor de uma teoria especulativa, a medicina transcendental, está no âmago do questionamento que os vitorianos faziam aos usos da ciência. Por outro lado, apesar de uma tentativa liderada pela própria rainha no sentido de manter os preceitos do anglicanismo, na última metade do século XIX, face os avanços científicos, boa parte dos vitorianos já havia perdido a fé nas formas tradicionais do Cristianismo. Esse estado de coisas revelou-se um terreno propício para a ascensão do ocultismo, cada vez mais popular em todas 
as camadas sociais. Uma verdadeira onda mística surgiu nessa época, bem como o gosto pela mágica e por fenômenos sobrenaturais (OWEN, 1990; 2003). Essa atração pelo insólito foi, com certeza, responsável pelo ressurgimento da literatura gótica no fin-de-siècle e pelo sucesso de $O$ Grande Deus Pã.

Machen foi sagaz ao entretecer a ciência no insólito, refletindo desse modo as inquietações dos vitorianos. Cartas trocadas entre Machen e seu editor, John Lane, dão conta da controvérsia gerada por esse primeiro capítulo, uma vez que Lane achava que deveria ser cortado. Como podemos observar na citação abaixo, o autor se manifesta contra qualquer corte:

O único "senão" é a sugestão de cortar o primeiro capítulo "O Experimento" e, com ele, o motivo, de $O$ grande deus Pã. A "credibilidade", todo o efeito da história repousa sobre isso. Se eu estivesse escrevendo na Idade Média, não precisaria de nenhuma base científica, porque naqueles dias o sobrenatural em si era totalmente confiável. Nestes dias, o sobrenatural em si é inteiramente incrível; para acreditar, devemos vincular nossas maravilhas a algum fato, fundamento ou método científico ou pseudocientífico. Assim, não acreditamos em "fantasmas", mas em telepatia, não em "feitiçaria", mas em hipnotismo. Se o Sr. Stevenson tivesse escrito sua grande obra-prima por volta de 1590-1650, o Dr. Jekyll teria feito um pacto com o diabo; em 1886 o Dr. Jekyll solicita aos químicos da Bon Street algumas drogas raras. (Selected Letters 218. Tradução nossa $)^{5}$

Embora seja clara a influência de Stevenson na elaboração do capítulo, é inegável a criatividade de Machen ao conjugar os saberes científicos ao misticismo, evocando uma dualidade que era cara aos vitorianos. A julgar pelo resultado, a princípio, o leitor crê no fracasso do experimento. O desfecho real da cirurgia só é revelado ao final, após vários capítulos em que o foco da atenção é desviado para outra personagem feminina, mulher misteriosa que leva à desgraça todos os homens que dela se aproximam. O modo abrupto com que Machen desvincula esse primeiro capítulo dos seguintes confunde o leitor, que se vê, subitamente, transportado para "uma outra história".

Passados alguns anos, já em Londres, Clarke, que tenta compilar um livro intitulado Memórias para Provar a Existência do Diabo, lê a narrativa de um amigo, Dr. Phillips, sobre estranhos acontecimentos ligados a uma moça do País de Gales, cujo nome é Helen Vaughan.

\footnotetext{
${ }^{5}$ The only case of 'won' $t$ ' is the suggestion to cut out the 1st chapter 'The Experiment' and with it the motive, from The Great God Pan. The 'credibility,' the whole effect of the story rest on this. If I were writing in the Middle Ages I should need no scientific basis for the reason that in those days the supernatural per se was entirely credible. In these days the supernatural per se is entirely incredible; to believe, we must link our wonders to some scientific or pseudo- scientific fact, or basis, or method. Thus we do not believe in 'ghosts,' but in telepathy, not in 'witchcraft,' but in hypnotism. If Mr. Stevenson had written his great masterpiece about 1590-1650, Dr. Jekyll would have made a compact with the devil; in 1886 Dr. Jekyll sends to the Bon Street chemists for some rare drugs. (Selected Letters 218).
} 
O tutor da jovem optara por enviá-la para ser educada por uma família de camponeses. Entretanto, desde a sua chegada, estranhos acontecimentos começaram a ocorrer na região. Dentre eles, o que envolveu um menino que enlouquecera após ver a estátua de um fauno em uma residência em que o pai trabalhava, associando-a, com terror, a um homenzinho nu a quem vira brincando com Helen na floresta. Rachel, a filha de um rico lavrador, igualmente, começara a ter um comportamento estranho após tornar-se amiga de Helen, até que um dia, em desespero, revelara à mãe os estranhos acontecimentos dos quais tomara parte na floresta. Pouco depois, a jovem desapareceu sem deixar rastros. Essa parte da história se passa exatamente na região agreste onde o autor nasceu e foi criado e são muitas as referências ao paganismo e aos resquícios de construções e estátuas romanas.

Logo, a narrativa dá outro salto temporal e entra em cena outra personagem, Villiers, que narra a Clarke o encontro que tivera com um velho amigo, Charles Herbert. Física e mentalmente abalado e visivelmente aterrorizado, Herbert lhe confidencia ter sido corrompido de corpo e alma por sua esposa, Helen, que, em seguida, desaparecera com tudo o que ele possuía. Villiers mostra a Clarke um retrato da mulher de Herbert, feito por um pintor que vivia na América do Sul, e este desconfia de que há uma ligação entre ela e os acontecimentos ocorridos em Gales. Também não lhe passa despercebida a semelhança física entre ela e a jovem que fora operada pelo Dr. Raymond. A essa altura, novas conexões são feitas pelo leitor, que percebe ser essa semelhança o indício de algum mistério ainda por desvendar.

A ação de Villiers na novela responde a outras características do público vitoriano: o interesse pela solução de mistérios e o fascínio pelo escândalo. Ao fazer de um cidadão de alta classe social o seu detetive amador, Machen preenche rapidamente uma lacuna que fora deixada pelas bem-sucedidas histórias de Conan Doyle sobre o detetive Sherlock Holmes, cujo último lançamento havia ocorrido no ano anterior.

A história prossegue e, após uma onda de suicídios de ricos cavalheiros em Londres, Villiers descobre que todos eles frequentavam a casa de certa Sra. Beaumont, recém-chegada da América. Investigando o paradeiro de Helen, Villiers acaba por descobrir que ela e a Sra. Beaumont são a mesma pessoa. Frequentadora dos lugares mais sórdidos da cidade, ela persuadia os homens a ações que os levava à loucura e à morte. O tema do Doppelgänger, ou seja, do duplo, que "aparece regularmente na literatura gótica como uma consequência da crença científica de que há certa dualidade interna em cada ser humano"6 (JÜNGER, 2008, p. 8, tradução nossa), é desse modo incorporado à novela.

\footnotetext{
6 "appears regularly in the Gothic literature, as a consequence of the scientific belief that there is a certain inner duality in every human being” (JÜNGER, 2008, p. 8).
} 
Há diversas passagens no texto em que rituais pagãos associados à Helen são evocados. Na citação a seguir, há uma explícita referência ao deus Pã:

- Está bem! Imagino o que leste e sei quão horrível é. Mas, apesar de tudo, é uma velha história, um mistério antigo recuperado em nossa época, com as ruas de Londres substituindo os antigos vinhedos e olivais. Sabemos o que acontecia a quem encontrasse o deus Pã. Os sábios acham que todo símbolo é duma realidade e não do nada. E era, na verdade, um símbolo bem refinado, esse, sob o qual os antigos velavam as forças secretas e terríveis que se escondem no coração de todas as coisas, perante as quais a alma humana se desvanece e morre, enegrecida, como o corpo ficaria se atacado por correntes elétricas. Essas forças só podem ser nomeadas e concebidas através dum véu que para a maioria não mais é que uma fantasia poética e pra alguns uma história contada por idiotas e loucos. Mas nós, tu e eu, conhecemos um pouco do terror que pode habitar os reinos secretos da vida, sob a aparência da carne. Vimos o informe assumir uma forma (MACHEN, 1986, p.43).

O modo como Machen constrói a narrativa em parceria com o leitor é, às vezes, surpreendente, se considerarmos a época em que a obra foi escrita. Ao longo da narrativa, há muitas situações que, embora referenciadas, não são descritas. Essas lacunas são abertas propositalmente para serem preenchidas pela imaginação do leitor, constituindo uma estratégia à qual Campra (2016, p.134) denomina "poética dos vazios". Outro exemplo marcante do uso que Machen faz do "silêncio" diz respeito à passagem que Rachel confessa à mãe o que ocorrera na floresta é suprimida:

Numa noite, contudo, depois de Raquel voltar, a mãe ouviu no quarto algo que lhe pareceu um choro abafado. Entrou e encontrou a filha meio despida, sentada na cama, tomada de indizível angústia. Ao ver a mãe, gritou: Ó! Mamã! Por que me deixaste ir com Helena à floresta? Espantada em ver a filha naquele estado, senhora M... a interrogou e Raquel contou uma história terrível. Disse... (MACHEN, 1986, p.13).

Segundo Navarette, em The Shape of Fear (1998), essa estratégia reflete a crença de Machen na inefabilidade da experiência não racional. Indubitavelmente, a escolha de Helen Vaughan como o centro de onde todas essas reflexões emanam passa pela questão da sexualidade, que estava sob escrutínio na Era Vitoriana.

Curiosamente, não há na novela personagens femininas com as características do "anjo do lar", que tão bem tifipica o ideal de mulher da época. Helen é descrita como a femme fatale e sua presença no universo ficcional desafia os códigos da moral vitoriana e da sociedade patriarcal. Dotttin-Orsini chama a atenção para o fato de que a "literatura da segunda metade do século XIX mostra claramente que a mulher mete medo, que é cruel, que pode matar". (ORSINI, 1996, p. 13) E é essa mulher assombrosamente atraente e perigosa que Helen 
encarna. Ela é a figura abominada pela moral vitoriana, porém a sedutora indispensável aos cavalheiros de boa estirpe. Como Paglia nos faz lembrar, o sexo "é o ponto de contato entre o homem e a natureza, onde a moralidade e as boas intenções caem diante de impulsos primitivos" (PAGLIA, 2005, p.15). Helen pode, então, ser interpretada também como uma expressão estética do medo masculino ante os movimentos que advogavam uma mudança do papel social da mulher à época.

Quando, no penúltimo capítulo, Helen é confrontada por Villiers e levada ao suicídio, a natureza inumana da personagem é finalmente revelada, pois ela passa por uma verdadeira metamorfose:

Se bem que atacado por uma náusea de revolta e quase sufocado pelo odor da corrupção, me mantive firme, privilegiado ou maldito, não sei, olhando o que ali estava, negro como tinta, e que se transformava perante meus olhos. Pele, carne, músculo e osso, e a firme estrutura do corpo humano, tudo o que, até então, considerara algo permanente como o diamante, começou a se fundir e dissolver. Sabia que agentes exteriores podiam assim devolver o corpo aos elementos mas me recusaria a crer naquilo que via porque havia ali uma força interna que eu não conhecia e que ordenara a dissolução e a metamorfose. Ali se repetiu, em minha frente, todo o esforço que originou o homem. Vi a coisa vacilar de sexo a sexo, se dividir e se unificar de novo. Vi o corpo regredir às feras que o precederam, o que estava na coroa dos seres descer ao inframundo, ao abismo. Mas o princípio da vida, que cria o organismo, permanecia estável no meio das transformações da forma [...] Eu olhava sempre: logo nada mais restava além duma substância semelhante à gelatina. E depois a escala foi de novo percorrida, em sentido inverso... (neste ponto são ilegíveis algumas linhas do manuscrito)... instante vi uma forma obscura à minha frente, que não quero descrever. Mas o símbolo pode ser encontrado nalgumas estátuas antigas e naquelas pinturas que sobreviveram à lava, demasiado infames pra que eu fale mais sobre elas... E a indizível aparência, homem e besta, retomou a forma humana. Então a morte sobreveio (MACHEN, 1986, p.46-47).

A androginia de Helen, revelada ao final, é explicada pelo Dr. Raymond: ela é o resultado desastroso do experimento realizado no primeiro capítulo; é a filha de Mary com o deus Pã; gerada por meio de uma experiência mística:

O que eu disse que Maria veria, ela viu, mas me esqueci de que ninguém pode contemplar impunemente o que viu. E também esqueci de que uma vez que se abre a casa da vida ela fica acessível àquilo que não podemos nomear e a carne humana pode se tornar o véu do inexprimível. Brinquei com forças desconhecidas e conheces o resultado. Helena Vaughan fez bem em se atar à corda e morrer, por horrível que sua morte tenha sido. - Aquele rosto enegrecido, aquela metamorfose que se fundia sobre o leito e que, sob nossos olhos, passava de mulher a homem, de homem a besta, e de besta a algo ainda pior, tudo o que testemunhaste, nada me espanta. O que o médico viu já vi, muito antes. Porque compreendi minha obra logo no dia em que a criança nasceu. Ainda tinha cinco anos e eu já a vira mais de cem vezes, brincando com o companheiro que sabes quem é. Foi, pra mim, uma angústia indescritível e constante. Alguns anos mais tarde, sentindo que não suportaria mais aquilo, mandei Helena Vaughan a outro lugar. Já sabes o que assustou Trevor no bosque. $\mathrm{O}$ resto da história e tudo o que foi descoberto por teu amigo eu já sabia a 
minha própria custa, do primeiro ao último capítulo. E agora, Helena se reuniu a seus companheiros (MACHEN, 1986, p. 50).

A personagem espelha o lado corrupto e lascivo da sociedade e traz à tona "o tema da sexualidade não normativa e suas representações, naturais e urbanas, como um horror que é atraente e abjeto - uma fonte de fascinação e uma causa de desgosto" para os vitorianos (REYNE, 2013, p. iv).

Segundo Reyne, o que Raymond chama de "visão do deus Pã" espelha o que Weir (1995) denomina "lost arché", ou seja, a origem perdida. As experiências pessoais de Machen e o seu fascínio pelo ocultismo e pelo paganismo exerceram forte influência sobre a sua obra. Entretanto, como Webb (2010) aponta, o uso de crenças não cristãs para criar o horror sugere que o resultado da interferência nos mistérios das religiões antigas pode não ser benéfico. Em O Grande Deus Pã há uma conexão deliberada com o mal. Não sem propósito, Clarke faz a seguinte reflexão quando ouve pela primeira vez a história de Helen: Et Diabolus incarnatus est, et homo factus est?

Ao final, a aparente incoerência do suicídio de Helen pode ser compreendida à luz do Zeitgeist $^{8}$, como o resultado de uma busca constante da sociedade "pela racionalidade apolínea em detrimento dos impulsos dionisíacos, que, por sua intensidade, seriam capazes de lançar o homem a um estado de caos e de barbárie" (FRANÇA \& SILVA, 2015, p. 53).

\section{Considerações finais}

Em $O$ Grande Deus Pã, Machen constrói uma narrativa em que os ritos de fertilidade da antiga Roma e a imagem fálica de Pan resultam em atos de comunhão psicossexual e em revelações aniquiladoras, que, no entanto, não são desveladas aos olhos do leitor (CARREIRA, 2017, p. 99). Se por um lado a presença do insólito confronta a concepção cristã de pecado, conferindo ao texto um caráter transgressor, por outro as transformações sofridas por Helen - de um sexo a outro, de humana à besta - no momento de sua morte, epitomizam questões que afetavam profundamente a sociedade inglesa do fim do século XIX, como, por exemplo, o medo associado à teoria evolucionista da degeneração 9 .

A estrutura da narrativa não linear, construída como caixinhas chinesas, cujos desdobramentos vão surgindo aos poucos e iluminando o que foi narrado anteriormente,

\footnotetext{
${ }^{7}$ E o Demônio encarnou, e o homem está feito.

${ }^{8} \mathrm{O}$ espírito da época.

${ }^{9}$ Para uma abordagem mais precisa do tema, sugere-se a leitura da dissertação de Geofrey Reiter, intitulada 'Man Is Made a Mystery': the Evolution of Arthur Machen's Religious thought'.
} 
colabora para a intensificação do mistério e do medo, o que de certo modo é metaficcionalmente sinalizado por Villiers:

Villiers sonhava com a história que acabara de ouvir, se perguntando se a ouvira até o fim:

— Não. Até o fim, não. Só o princípio. Uma história dessa é como aquelas caixinhas chinesas: Se abre uma dentro da outra e se encontra tarefa cada vez mais bizarra. E possível que o pobre Herberto seja apenas uma das caixinhas exteriores: ainda falta abrir caixas muito mais estranhas (MACHEN, 1986, p. 18)

Conforme apontado anteriormente, essa arquitetura textual, que é também permeada de lacunas, visa objetivamente a conferir à novela uma semelhança com as histórias de detetive, e Machen une magistralmente a tessitura da diegese aos acontecimentos insólitos, ou seja, à presença do ser mítico que é o próprio Pã e à personagem híbrida e metamórfica cuja história é o fio condutor da narrativa. O fantástico ${ }^{10}$ surge, assim, como um meio de conferir à estrutura da história de detetive a atmosfera de horror típica da literatura gótica, que no fim do século XIX passava por um dos seus períodos de reavivamento, conforme atesta Botting (2005).

Machen, que aspirava ao reconhecimento alcançado por muitos autores decadentistas, não se deixou abalar pelas críticas recebidas à época e, de modo bem-humorado, as rebateu na introdução a uma nova edição da novela. A comoção causada pelo lançamento do livro efetivamente lhe proporcionara a atenção da crítica e do público, mas paradoxalmente os elementos que aproximavam a sua escrita do decadentismo levaram-no a amargar a obscuridade nos anos seguintes (SUTHERLAND, 1990). O Grande Deus Pã era controverso demais para uma sociedade que fora literalmente sacudida pelo escândalo envolvendo Oscar Wilde.

\section{REFERÊNCIAS}

BOTTING, Fred. Gothic. Londres: Taylor \& Francis e-Library, 2005.

CAMPRA, Rosalba. Territórios da ficção fantástica. Rio de Janeiro: Dialogarts, 2016.

CARREIRA, Shirley. Relações entre o insólito e os leitores empírico e virtual. Caderno Seminal Digital, Rio de Janeiro, Ano 16, no 14, V. 14, pp. 102-115, Jun. - Dez. 2010.

DOTTTIN-ORSINI, Mireille. A mulher que eles chamavam fatal: textos e imagens da misoginia fin-de-siècle. Rio de Janeiro: Rocco, 1996.

FOUCAULT, Michel. Microfísica do poder. Tradução de Roberto Machado. Rio de Janeiro: Edições Graal, 2010.

\footnotetext{
${ }^{10}$ Aqui compreendido segundo a concepção de Roas (2017), isto é, como o desvendamento daquilo que entranhado no contexto real e cotidiano do leitor, ao qual a ficção se assemelha, o interroga e o desestabiliza.
} 
FRANÇA, Júlio; SILVA, Daniel. De perseguidas a fatais: personagens femininas, sexo e horror na literatura do medo brasileira. Opiniães, São Paulo, v. 5, n. 6-7, p. 51-66, 2015. HOBSBAWM, E.J. The age of revolution: 1789-1848. New York: Mentor, 1962.

HUYSMANS, J. K. À rebours: le drageoir aux épices. Paris: Christian Bourgeois, 1975. JÜNGER, Mathias. Elements of a Gothic novel in The picture of Dorian Gray. Köln, 2008. LOVECRAFT, Howard Phillips. O horror sobrenatural na literatura. Tradução João Guilherme Linke. Rio: Francisco Alves, 1987.

MACHEN, Arthur. O grande deus Pã. Tradução de E. Leão Maia. Lisboa: Vega, 1986. MONTEIRO, Maria Conceição. Figuras errantes na época vitoriana: a preceptora, a prostituta e a louca. Fragmentos, v. 8, n. 1, p. 61-71, Florianópolis, jul. - dez. 1998.

NAVARETTE, Susan J. The shape of fear: horror and the Fin de Siècle culture of decadence. Lexington: University of Kentucky Press, 1998.

OWEN, Alex. The darkened room: women, power, and spiritualism in late Victorian England. London: Virago, 1989.

.The place of enchantment: British occultism and the culture of the modern. Chicago: U. of Chicago Press, 2003.

PAGLIA, Camille. Personas sexuais: arte e decadência, de Nefertite a Emily Dickinson. Tradução de Marcos Santarrita. São Paulo: Companhia das Letras, 1992.

REITER, Geofrey. "Man is made a mystery": the evolution of Arthur Machen's religious thought. 2010. Dissertation (Philosophy) - Baylor University, Waco, Texas.

REYNE, Jeffrey Michael. Panic on the British borderlands: The great god Pan, Victorian sexuality, and sacred space in the works of Arthur Machen. 2013. Dissertation (Philosophy) Temple University, Philadelphia.

ROAS, David. A ameaça do fantástico: aproximações teóricas. Tradução Julián Fuks. São Paulo: UNESO digital, 2017.

SUTHERLAND, John. The Longman companion to Victorian fiction. Essex: Longman, 1990.

WEIR, David. Decadence and the making of modernism. Amherst: University of Massachusetts Press, 1995.

Recebido em 28/08/2018. Aceito em 24/10/2018. 